\title{
CEFD \\ CENTRO DE EDUCAÇÃO \\ FÍSICA E DESPORTOS
}




\section{A Apresentação como Ferramenta Pedagógica no Ensino da Ginástica Rítmica}

\section{RESUMO:}

A Ginástica Rítmica (GR) combina elementos corporais ao manejo de apareIhos, os quais são contextualizados e executados de forma harmoniosa com acompanhamento musical (TOLEDO, 2016). Conforme Pallarés (1983), assim que os movimentos são dominados, é possível desenvolver composições caracterizadas pela busca de uma unidade estrutural e rítmica, na qual elementos da série se sucedem em equilíbrio, harmonia e fluência. E, no processo de ensino-aprendizagem, aspectos como a cooperação, a integração, a interação e a coordenação entre os alunos que conformam o grupo são essenciais, principalmente, nas apresentações e competições. Desde 2016, o Núcleo de Pesquisa em Ginástica (NPG) organiza o projeto de extensão de Ginástica Rítmica, o qual é direcionado para crianças entre 7 e 12 anos. Destacamos, fundamentados em Gaio (2007), que visamos propiciar acesso à vivência dessa modalidade com a promoção da consciência corporal e da formação do indivíduo perante o mundo, por meio das seguintes ações: descoberta de suas possibilidades de expressão; o desenvolvimento da noção espacial; a estruturação da noção temporal; e o desenvolvimento afetivo-social. No primeiro semestre de 2018, as alunas do projeto participaram do Festival de Ginástica Rítmica organizado pela Federação Espírito-Santense de Ginástica. Sabemos que no esporte, a competição é um elemento que dá sentido a sua existência e, segundo Reverdito et al. (2008), é nela que o fenômeno esportivo se realiza em toda sua plenitude. Corroboramos Ferraz (2002, p. 37) que "a competição em si não é boa ou má, ela é o que fazemos dela”. Fundamentados nessa premissa, consideramos que competir ou se apresentar pode se constituir em uma importante ferramenta pedagógica, na qual as jovens ginastas aprendem e interagem com seus pares demonstrando o seu potencial. Trata-se, também, de um momento memorável, tanto na vida delas quanto dos familiares, que podem visualizar os resultados do trabalho desenvolvido no ginásio. 


\title{
A Coreografia na Ginástica para Todos: Autores e Atores do Espetáculo
}

\begin{abstract}
RESUMO:
Ao analisarmos a Ginástica Para Todos (GPT), observamos que se trata de uma modalidade gímnica que permite o diálogo entre as diferentes manifestações de ginástica numa perspectiva lúdica, criativa, participativa e inclusiva (GRANER, 2013). Ademais, podemos compreendê-la como uma manifestação da cultura corporal que integra de forma livre e fecunda a ginástica com outras formas de expressão corporal, como: dança, teatro, mímica, jogos, folclore (GALLARDO; SOUZA, 1997) e, podemos acrescentar, o circo. Paoliello (1997) classifica a GPT como uma Ginástica de Demonstração, a qual não possui fins competitivos com caráter participativo. Tendo em vista essas características, assim como o seu potencial de propiciar a (re)significação da ginástica, o Núcleo de Pesquisa em Ginástica (NPG) coordena o Grupo Ginástico "Meraki”, o qual oferta a prática da GPT para alunos dos cursos de licenciatura e bacharelado em Educação Física. Ayoub (2003) ressalta que a apresentação de coreografias é um aspecto inerente à modalidade. E, segundo a autora, a coreografia representa uma síntese do trabalho desenvolvido coletivamente pelo grupo durante um determinado período. No ciclo 2017/2018, o Grupo Ginástico "Meraki" elaborou duas coreografias que constituíram uma parte integral do processo educativo da GPT. Graner (2013) destaca que no processo de criação, todos os participantes são "coreógrafos", ou seja, são autores e ao mesmo tempo atores do espetáculo, prevalecendo o princípio da coautoria. Isso fortalece os laços sociais entre os ginastas do grupo, em busca de autoconhecimento e superação, individual e coletiva (SOUZA, 1997). A troca constante de ideias durante o processo criativo deve nortear o trabalho do grupo em busca de uma produção original, tendo a ginástica como seu meio (SANTOS, 2009). Nesse momento de construção coreográfica, a expressão "uma ginástica para e por todos" (OLIVEIRA; SILVA; SILVA, 2018) se materializa e adquire real significado para os membros que constituem o grupo.
\end{abstract}




\section{Brinquedoteca - Aprender Brincando}

PINTO A.G. MOTTA, R.C. FREITAS, R.R LEANDRO, J.S. SANTOS, R.S. MURACA, G.V CHICON, J.F.

\section{INTRODUÇÃO}

O Projeto "Brinquedoteca: aprender brincando", desenvolvido no Laefa-Ufes, consiste em um espaço de intervenção pedagógica, formação profissional e de ensino, pesquisa e extensão no atendimento de crianças com e sem deficiência em processo de inclusão. O projeto objetiva promover campo de estágio aos acadêmicos, expandir os serviços de Educação Física a comunidade de crianças com e sem deficiência, incrementar a prática de ensino e pesquisa nessa área de interesse, com orientação teórico metodológica na abordagem histórico cultural.

\section{METODOLOGIA}

O atendimento é realizado com 55 crianças, de 3 a 6 anos, sendo 40 do Centro de Educação Infantil Criarte-Ufes, uma com síndrome de Down e 14 com autismo da comunidade, constituindo turmas inclusivas para explorar os brinquedos, realizar brincadeiras e experimentar diferentes formas de se movimentar e se relacionar em duas atividades: "Aprender brincando" e "Brincando e aprendendo com a ginástica. Os atendimentos são realizados todas as segundas e quintas-feiras, das 14 às $15 \mathrm{~h}$. Das 15 às $17 \mathrm{~h} 30 \mathrm{~min}$, a equipe de trabalho se reúne para estudo, avaliação e planejamento.

\section{RESULTADOS}

Quantitativamente realizamos 880 atendimentos semestrais, publicamos 1 livro, 5 artigos em revista, 3 capítulos de livro, 2 IC e 2 TCC. Os acadêmicos adquiriram experiência prático/teórica do exercício da função docente no atendimento educacional de crianças com e sem deficiência na brinquedoteca. Observamos que crianças com deficiência adquiriram mais independência e autonomia, melhorando a autoestima. O projeto é campo para estágio supervisionado em Educação Física e Lazer e disciplina de práticas inclusivas (licenciatura).

\section{CONCLUSÃO}

O projeto supre uma lacuna social existente na comunidade em relação à ausência de oferta de serviços públicos e privados no âmbito socioeducacional para crianças com deficiência, melhorando a qualidade de vida dessas pessoas. Fomenta princípios que contribuem para uma sociedade que não só reconheça a diversidade humana, mas a conceba como uma premissa de vida. 


\section{Do Mar para Ufes: Experiência Colaborativa de Organização de um Evento de Natação}

\section{INTRODUÇÃO}

Considerando que a natação é um esporte elitizado no Brasil, já que o acesso às piscinas para aprendizagem e treinamento da modalidade é restrito, o projeto Práticas de Natação tem como objetivo ofertar um espaço democrático para dedicação a essa prática no âmbito da UFES. Problematizando essa questão com os alunos inseridos no projeto, uma vez que o mesmo também é insuficiente para atender a toda a demanda da região, decidimos coletivamente organizar um evento aberto à comunidade interna e externa que democratizasse pontualmente o acesso às instalações de treinamento da UFES e incentivasse pessoas a praticarem a modalidade. Essas ideias se tornaram a construção colaborativa do I Biathlon de Verão da UFES, sobre o qual este trabalho tem por objetivo relatar a experiência.

\section{METODOLOGIA}

Para tanto, utilizamos a proposta de Jara-Holliday (2006), de sistematização da experiência.

\section{RESULTADOS}

A inquietação para a organização do evento, surgiu de diálogos com nossos alunos sobre a possibilidade de integrar ao projeto, mesmo que pontualmente, outros sujeitos da comunidade engajada com a natação da grande Vitória, com os quais estes alunos começaram a ter acesso na medida em que foram se envolvendo em nosso projeto. A ideia seria expandir as possibilidades do projeto. A construção coletiva se deu quando chegávamos antes dos treinos, para discutir detalhes e propostas. Por meio de nossos alunos, pudemos entrar em diálogo com coletivos de natação, como os Nadadores do Mar, o Sóvem e os Atletas da Ilha. Tais relações foram fundamentais para ampliar o alcance do projeto e do evento, bem como criar uma sinergia maior entre universidade e comunidade externa.

\section{CONCLUSÃO}

A realização do evento materializou o espírito extensionista, pois os participantes do projeto foram sujeitos protagonistas da organização do evento e possibilitaram ampliar ainda mais o diálogo e as trocas entre universidade e sociedade. 


\section{Outros Olhares no Projeto "Cuidadores que Dançam": A Mulher para Além do Cuidado e a Dança para Além da Técnica}

SOUZA, J.C.S. SILVA, E. M.

\section{RESUMO:}

Na sociedade, foram construídos e são reproduzidos cotidianamente preceitos que regram a condição da mulher, direcionando-as às atividades como a do cuidado de pessoas. Esse papel desempenhado é um elemento estrutural da sociedade que se construiu majoritariamente como feminino (MARCONDES, 2013). No cuidado, a abdicação dos próprios desejos e necessidades se transfigura como algo comum na medida em que o cuidar de outro indivíduo se torna algo preponderante e que se agudiza quando o cuidado é voltado para indivíduos com deficiência. Em contrapartida a essa condição feminina e a esses paradigmas sociais, o projeto "Cuidadores que Dançam" foi criado em 2011 com o objetivo de atender cuidadoras das pessoas com deficiência que participam de um laboratório de Educação Física adaptada, propiciando "um espaço/tempo para que as participantes tenham um momento de descoberta de si em contexto de descontração e aprendizado a partir das diversas formas de dança" (SILVA et al., 2016, p. 891). A Dança, por sua vez, também é problematizada nesse projeto visto que, não raro, é concebida como uma prática distante e de difícil acesso, com determinações que deixam a interpretar que só é possível dançar com uma técnica perfeita e específica. Pensando para além disso, o projeto mostra diversas possibilidades de trabalhar com a dança em uma relação contextualizada e direta com os sujeitos para uma compreensão crítica do mundo, libertação e ressignificação identitária, sem ignorar os relacionamentos/sentimentos/ sensibilidade "humanos" (MARQUES, 2011). Assim, o trabalho de cunho qualitativo que utiliza como instrumentos para recolha de dados os planos de intervenções, planos de aulas, e relatórios referentes aos semestres 2017/2 e 2018/1, fundamentando-se nas análises de conteúdo, busca apresentar como se desenvolve a metodologia de ensino utilizada no espaço/tempo oportunizado pelo projeto e suas intenções em relação às suas participantes. 


\section{Para além da Ginástica: Reflexões Sobre a Formação Humana na Prática Gímnica}

\section{RESUMO:}

A ginástica tem o potencial de proporcionar um ambiente de prática que consente aos seus praticantes a experimentação de seus corpos em atividades diferenciadas e diversificadas com a interação ou não com objetos, aparelhos e outras pessoas. Segundo Nunomura (2016), na prática gímnica o aluno é exposto a uma série de movimentos e situações que possibilitam o desenvolvimento motor, físico, afetivo, social e cognitivo. Tendo em vista essa potencialidade, o Núcleo de Pesquisa em Ginástica (NPG) coordena o projeto de extensão intitulado Escolinha de Iniciação à Ginástica, para crianças de 7-12 anos, com a finalidade de propiciar a prática democrática da ginástica para a comunidade externa à Universidade. O projeto desenvolve essa manifestação corporal com o intuito de proporcionar o bem-estar físico, psicológico e social dos jovens ginastas tendo como premissa a filosofia dos 4Fs (Fun, Fudamentals, Fitness e Friendship) proposta por Russell (2014). Por meio do ensino dos fundamentos da ginástica, oferecemos ferramentas essenciais para o aprendizado de habilidades complexas de diferentes modalidades de ginástica e, além disso, proporcionamos aos alunos a aquisição de competências importantes para a vida em geral, não se limitando ao âmbito esportivo, e que serão utilizadas em atividades cotidianas (NUNOMURA, 2005). Ademais, corroboramos Hirama, Joaquim e Montagner (2011) que, por meio de uma pedagogia do esporte bem estruturada, é possível desenvolver aspectos atitudinais importantes e que incidem de forma preponderante na formação dos alunos dentro e fora do fenômeno esportivo. Mas, para que isso ocorra, os autores destacam a necessidade de um planejamento, pois isso não ocorre de forma natural, sem controle, no âmbito esportivo. Assim, primamos desenvolver nos participantes do projeto o senso de responsabilidade, respeito, disciplina, paciência, empatia, altruísmo e cidadania que são aspectos essenciais para a formação de indivíduos saudáveis e atuantes na sociedade. 


\section{Projeto Capoeira UFES}

JANDOSO JUNIOR, R. N, NASCIMENTO, A. C.S. LOUREIRO, F. L.

\section{INTRODUÇÃO}

O Projeto Capoeira UFES é desenvolvido há 39 anos e, no decorrer desse período, vem contribuindo para a formação e para o desenvolvimento pessoal dos acadêmicos envolvidos no projeto, ampliando seus conhecimentos teórico-práticos sobre o ensino da capoeira. Além disso, se consolidou como importante ação de divulgação e valorização da cultura popular afro-brasileira. Ao oferecer às comunidades interna e externa a possibilidade de vivência da capoeira, o projeto se apresenta, para os acadêmicos, como importante espaço de reflexão, construção/reconstrução de princípios e valores no ensino da capoeira, se constituindo, também, como profícuo campo de pesquisa e de produção de conhecimento.

\section{METODOLOGIA}

Busca desenvolver os principais elementos da capoeira, tais como gestualidade, musicalidade, expressividade, ritualidade, além dos aspectos históricos, culturais e técnicos voltados para o desenvolvimento integral do indivíduo dentro de um contexto lúdico e envolvendo os aspectos ligados à criatividade individual e coletiva. As aulas têm duração de uma hora a uma hora e quarenta minutos e respeitam o nível de desenvolvimento dos alunos de cada faixa etária.

\section{RESULTADOS}

Produção de trabalhos acadêmicos que receberam contribuições dos responsáveis pelo projeto nos anos anteriores, por meio das orientações de pesquisas e de monitorias. Além disso, foram registrados a apresentação de trabalhos em congressos e outros eventos; a publicação de artigos; a divulgação das atividades no site e Jornal da UFES. Apresenta, também, um impacto social, ao construir um espaço de aprendizagens, tanto para os acadêmicos envolvidos como para a comunidade em geral, trabalhando diferentes linguagens culturais próprias do universo afro-brasileiro.

\section{CONCLUSÃO}

Além de contribuir para a qualidade de vida dos praticantes, por meio do trabalho de condicionamento físico, o projeto promove a formação cultural e humana ao valorizar a diversidade cultural, integrando diferentes perspectivas e linguagens e se consolidando como espaço de produção cultural e de conhecimento. 


\section{Projeto de Extensão Grupo Andora: Formação e Sua Representação Social}

\section{RESUMO:}

Esse trabalho é fruto de uma pesquisa de um trabalho de conclusão de curso que buscou investigar a Representação Social do Projeto de Extensão Grupo Andora (PEGA) e analisar suas contribuições para a formação inicial dos extensionistas do PEGA e graduandos do Centro de Educação Física e Desportos (CEFD). Foi utilizado como referencial teórico a Teoria das Representações Sociais para identificar qual é a representatividade do PEGA a partir dos sentidos atribuídos dos sujeitos que o constrói e compreender qual é a sua significação para os sujeitos que fazem parte do PEGA. Para participar da pesquisa foi necessário realizar um levantamento de dados para classificar os sujeitos. Foram encontrados mais de 52 professores formados pelo CEFD - UFES que participaram do PEGA, mas para participar da pesquisa esses sujeitos deveriam ter no mínimo alguma experiência profissional como professor de qualquer espaço de educação seja formal ou não para participar da pesquisa. Ao final contabilizamos 33 professores que se encaixam dentro dessa característica. Todos os 33 professores aceitaram participar da pesquisa. Aplicamos o questionário eletrônico e tivemos um retorno de 13 questionários respondidos que correspondem a 40\% dos 33 questionários enviados. Após a análise dos dados identificamos a Representação Social do PEGA e seus elementos centrais que dão origem ao Núcleo Central (NC). O NC é motivo pelo qual as pessoas pertencem a um determinado grupo e no PEGA o NC é constituído pelos elementos: espaço afetivo, formação docente, formação humana e cultura como eixo. São esses elementos que dão sustentação e origem a Representação Social do PEGA. Os outros elementos que compõem a Representação Social do PEGA como os periféricos (EP) e os distantes (ED) reforçam a representatividade da formação do NC. 


\section{Projeto Saúde e Bem-Estar no Cefd: Avaliação do Perfil Antropométrico e Cardiovascular dos Servidores Técnico Administrativos do CEFD}

MELLO, I.A CARLETTI, L. LIMA, A.P.L. DEMIAN, M.V. MAUAD, $H$ SILVA, O.G.T CUNHA, M.R.H.

\section{INTRODUÇÃO:}

Promover comportamentos de saúde no ambiente de trabalho reduz a prevalência de enfermidades e de ausências, o número de acidentes, melhora o ambiente organizacional, aumentando a qualidade e produtividade. As doenças crônicas não transmissíveis (DCNT) são as principais causas de morte no mundo, correspondendo a 16 milhões de mortes prematuras antes dos 70 anos. As causas dessas doenças incluem fatores de risco modificáveis, como tabagismo, consumo nocivo de bebida alcoólica, inatividade física e alimentação inadequada. Os servidores do CEFD apresentam carência de informações sobre as problemáticas acima, tornando importante o acesso a essas informações para redução e prevenção das DCNTs.

\section{METODOLOGIA}

Participaram dezesseis servidores. Realizaram teste ergométrico, responderam um questionário sobre qualidade de vida e foram submetidos à avaliação antropométrica para que fosse possível analisar o quadro de saúde de cada indivíduo, a fim de orientá-los individualmente para a prática de atividades físicas. Os resultados foram expressos como Média土EPM.

\section{RESULTADOS}

Do total de participantes, 8 eram mulheres (idade $=46,5 \pm 3,89$ anos; altura $=1,58 \pm 0,057 \mathrm{~m}$; peso=66,75 $\left.\pm 21,2 \mathrm{~kg} ; \quad I M C=26,7 \pm 7,3 \mathrm{~kg} / \mathrm{m}^{2}\right)$ e 8 homens

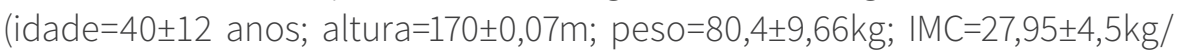

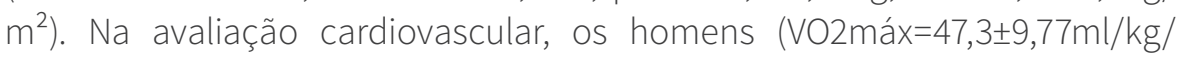
min; $F C=173 \pm 23,6 \mathrm{bpm}$; PAS=171,3 $\pm 23,6 \mathrm{mmHg}$; $P A D=78,8 \pm 11,26 \mathrm{mmHg}$; MET$\mathrm{s}=13,52 \pm 2,8 \mathrm{~mL} / \mathrm{kg} / \mathrm{min}$;Duploproduto=29698,8 $\pm 5305,5 \mathrm{bpm} . \mathrm{mmHg}$ ) apresentaram resultados levemente melhores que as mulheres (VO2máx $=32 \pm 7,85 \mathrm{ml}$ ) $\mathrm{kg} / \mathrm{min} ; \quad F C=164,4 \pm 10,2 \mathrm{bpm} ; \quad P A S=148,8 \pm 17,3 \mathrm{mmHg} ; \quad P A D=71,3 \pm 9,9 \mathrm{mmHg}$; METs=9,15 $\pm 2,24 \mathrm{~mL} / \mathrm{kg} / \mathrm{min}$; Duplo produto=24413,8 $\pm 2923,7 \mathrm{bpm} . \mathrm{mmHg}$ ).

\section{CONCLUSÃO}

Os dados antropométricos indicam baixa prevalência de sobrepeso e obesidade, reduzindo o risco do acometimento de DCNTs. A avaliação cardiovascular sugere um perfil saudável dos servidores do CEFD, com apenas 2 participantes apresentando dados ligeiramente abaixo dos valores de referência. Estas informações apontam a prevalência de indivíduos metabolicamente e funcionalmente saudáveis no corpo de servidores do CEFD. 


\section{Projeto Vida Saudável}

\section{INTRODUÇÃO:}

O projeto de extensão Vida Saudável (PVS) é uma proposta multidisciplinar que visa melhorar a qualidade de vida de indivíduos obesos, diabéticos e cardiopatas por meio da promoção de saúde. Dentro desse contexto, visa promover a prevenção e o controle de doenças crônicas não-transmissíveis (DCNTs) por meio de intervenções físicas, acompanhamento nutricional e ações educacionais.

\section{METODOLOGIA}

A duração do projeto é de 2 anos, sendo iniciado em 01/08/2017 e término previsto para 07/2019. A população até o presente momento foi de 115 participantes de ambos os sexos, de faixa etária acima de 18 anos, portadores de DCNTs, classificadas a partir de Diretrizes Específicas e Organização Mundial de Saúde. O público selecionado é proveniente das comunidades interna e externa da UFES e dos municípios da grande Vitória/ES. Os participantes passaram por avaliações clínicas, estado nutricional, aptidão física, flexibilidade e padrão funcional de movimento antes de ingressarem e a cada 3 meses. As intervenções físicas foram realizadas nas instalações do Centro de Educação Física e Desportos e do Núcleo de Pesquisa e Extensão em Ciências do Movimento Corporal/NUPEM.

\section{RESULTADOS}

Observa-se que vários participantes apresentaram melhora da composição corporal, diminuição dos níveis glicêmicos e pressóricos, mudanças no padrão de movimento, hábitos nutricionais e convívio social. O projeto também contemplou palestras e ações educacionais, entre elas: "Você sabe comer?" e "Motivação".

\section{CONCLUSÃO}

O PVS promove diversos aspectos benéficos relacionados à nutrição saudável, ao perfil dislipidêmico e à prática de atividade física, contribuindo sensivelmente para diminuição da mortalidade e aumento da qualidade de vida. Em adição, atua na formação e suporte acadêmico a partir do oferecimento de campos de estágio voluntário e supervisionado, complementando conhecimentos adquiridos na teoria e aplicando-os na prática. O PVS proporciona a criação de banco de dados, possibilitando a realização de pesquisas de TCCs e no âmbito da Pós-Graduação. 


\section{Talento Praiano: Futebol de Areia para Crianças e Jovens}

COSTA, O. P. OLIVEIRA, U.

\section{INTRODUÇÃO:}

O futebol de areia é uma modalidade bastante popular no Espírito Santo. De acordo com sua federação, estima-se que existam cinco mil atletas federados na modalidade no Estado. O presente projeto de extensão busca fomentar um ambiente público de ensino-aprendizagem-treinamento desta modalidade propondo metodologias inovadoras, direcionado a crianças e jovens da região.

\section{METODOLOGIA}

O projeto foi desenvolvido na praia de Camburi em Vitória, as terças e quintas-feiras, das 14 as 17h. A metodologia de ensino tem caráter inovador sugerida por Greco e Benda (1998), fundamentada numa visão humanista. As primeiras aulas foram diagnósticas, com o objetivo de observar o nível de entendimento sobre o futebol de areia para propor futuras intervenções. Para isso foi levado em consideração a compreensão do jogo através de suas estruturas funcionais que foram decompostas e posteriormente modificadas quanto ao espaço, ao número de jogadores e alvos, contemplando objetivos de acordo com o nível de complexidade. Isto nos levou a apresentar fases diferenciadas na proposta de atividades, indo do simples para o complexo, da percepção geral a específica, dificultando a cada nível posterior.

\section{RESULTADOS}

Percebeu-se que os alunos entenderam a metodologia, com isso não tratavam o gesto técnico como prioridade, mas sim o prazer pelo jogo. Os mais antigos, levavam o jogo para o seu caráter lúdico incentivando e estimulando os colegas mais novos. Isso acontecia inicialmente devido à dificuldade em que os novos praticantes de futebol de areia têm para se adaptar ao ambiente, o que pode levar ao desânimo em continuar na prática e posteriormente levá-los a desistência.

\section{CONCLUSÃO}

Concluímos que o protagonismo individual proposto pela metodologia conseguiu construir coletivamente olhares mais amplos, tornando o processo de adaptação e consolidação da modalidade mais tranquila para os seus praticantes, consequentemente a socialização e a motivação se tornaram importantes aliados nas práticas propostas. 